\title{
Glucose, Insulin, and Triglyceride Responses to High and Low Carbohydrate Diets in Man*
}

\author{
John W. Farquhar, $\dagger$ Arthur Frank, $\$$ Richard C. Gross, $\S$ and Gerald M. \\ REAVEN With THE TECH NICAL assistance OF E. P. BRoWN \\ (From the Department of Medicine, Stanford University School of Medicine, Palo Alto, Calif.)
}

Several reports have recently been published which suggest that abnormalities of glucose metabolism are common in patients with fasting hypertriglyceridemia. Metabolic defects reported in these patients have included abnormal glucose $(1,2)$ and tolbutamide tolerance tests $(3)$, and a diminished blood glucose response to exogenous insulin $(2,4)$. However, conflicting reports have been obtained in measurements of endogenous plasma insulin response to oral glucose loads in hypertriglyceridemic patients. Kane, Longcope, Pavlatos, and Grodsky have reported normal insulin levels measured by bioassay and immunoassay (2). On the other hand, preliminary reports from our group and from Davidson and Albrink suggest that elevated plasma insulin is a common response in such subjects when measured either by bioassay $(5,6)$ or immunoassay $(6,7)$. Although further evidence for abnormal insulin metabolism is suggested by the report of supranormal increases in plasma insulin-like activity after intravenous tolbutamide (3), tolbutamide's effect on insulin metabolism is not well understood and is clearly not analogous to the effect of ingested carbohydrate.

* Submitted for publication March 28, 1966; accepted July 14, 1966.

Presented in part at the national meeting of the American Federation for Clinical Research, Atlantic City, N. J., May 1965.

Supported in part by U. S. Public Health Service research grants AM 05972 and HE 08506 from the National Institutes of Health, K3-HE-6003 from the Career Development Review Branch, and FR-70 from the General Clinical Research Centers Branch, Division of Research Facilities and Resources.

† Address requests for reprints to Dr. John W. Farquhar, Stanford University School of Medicine, Stanford Medical Center, 300 Pasteur Drive, Palo Alto, Calif.

$\ddagger$ Postdoctoral research fellow, U. S. Public Health Service.

§ Postdoctoral research fellow, U. S. Public Health Service; present address: Karolinska Hospital, King Gustav V Research Institute, Stockholm 60, Sweden.
These differences in published results may be partly due to variations in experimental design and patient selection. Since plasma triglycerides are known to vary greatly depending on the amount and type of carbohydrate fed in isocaloric feeding programs $(8,9)$, dietary control should aid in establishing the relative degree of triglyceride abnormality in patient groups. Only one study has included such careful dietary control, but glucose and insulin-like activity were measured together only after intravenous tolbutamide (3). Furthermore, since plasma triglycerides are altered after chronic ingestion of these diets, insight into possible mechanisms of the hypertriglyceridemia might come from postprandial measurements of plasma glucose and insulin on defined diets.

In the study we report here, patients were selected with varying triglyceride levels as measured on ad libitum diets, and their insulin and glucose responses to an oral glucose load were measured. They were then placed on isocaloric liquid formula diets, varying only in percentage of fat and carbohydrate, and insulin and glucose studies were repeated in direct response to these meals. Patients with fat-induced lipemia (8) were excluded by dietary means and measurement of plasma postheparin lipolytic activity.

This paper confirms preliminary evidence (5-7) that hyperinsulinemia is a common response to single oral glucose loads in patients with hypertriglyceridemia. We also extend these observations to conclude that there is a high correlation between the magnitude of triglyceride response to high and low carbohydrate diets and the plasma insulin and glucose response to these diets.

\section{Methods}

Subjects. Table I summarizes the clinical features of the 15 experimental subjects. Two patients had psoriasis (W.W. and E.M.), and the remaining 13 had clinical evidence for premature atherosclerosis. All were ambu- 
latory, and their fasting blood glucose concentrations were less than $100 \mathrm{mg}$ per $100 \mathrm{ml}$.

Procedures. Calories were supplied in four daily equicaloric feedings of a liquid formula diet (10). Two diets were used; each contained $15 \%$ of calories from protein. One diet was high in fat ( $68 \%$ of calories), and the other was high in carbohydrate ( $85 \%$ of calories). All of the protein was derived from skimmed milk powder. ${ }^{1}$ In both diets $17 \%$ of calories were from the carbohydrates of skimmed milk powder, and these carbohydrates were composed of over $99 \%$ lactose and less than $0.5 \%$ monosaccharides. Fat and carbohydrate were varied by equicaloric replacement of corn oil ${ }^{2}$ and dextrins. ${ }^{3}$ The carbohydrates of the Dexin are obtained by partial hydrolysis of starch, yield entirely glucose on complete hydrolysis, and consist of the following components : $62 \%$ dextrins, $18 \%$ maltodextrins, and $19 \%$ maltose. All subjects were fed the high fat diet for 2 to 10 weeks and the high carbohydrate diet for $2 \frac{1}{2}$ to 7 weeks. In seven subjects the two diet program was repeated one or more times, and in eight subjects $125 \mathrm{mg}$ per day of chlorpropamide was given during a repeat feeding study. The duration of ingestion of each formula was considered an important variable, and care was taken to ensure that it was consumed steadily over a 30 -minute period. Finally, body weight was closely maintained to within $\pm 0.5 \mathrm{~kg}$ during each dietary period. A rapid gain or loss of approximately $1.0 \mathrm{~kg}$ occurred on shifting from a high fat to a high carbohydrate diet, or vice versa. This weight difference, presumed to result from

1 Carnation Instant, Carnation Co., Los Angeles, Calif. 2 Mazola, Corn Products Co., New York, N. Y.

3 Dexin, Burroughs Wellcome \& Co., Tuckahoe, N. Y. gain or loss of fluid, was maintained during the duration of either diet (Table I).

Oral glucose tolerance tests were performed on all patients immediately before the dietary studies. Concentrations of blood glucose (11), plasma immunoreactive insulin, 4 and insulin-like activity (12) were determined on the fasting, 1-, 2-, and 3-hour samples of the glucose tolerance tests. After the diet periods started, blood was drawn at 8 a.m. twice weekly; the plasma lipids were extracted with chloroform: methanol (13) and analyzed for total cholesterol (14), phospholipid (15), and triglyceride by a modification of the method of Lofland (16). During one of the paired high fat, high carbohydrate periods, additional measurements of plasma glucose (17) and immunoreactive insulin (18) concentrations were obtained in ten subjects. These studies, termed "all-day" insulin-glucose tests, were performed after 2 to 3 weeks of each dietary period and before termination of these periods. The patients ingested their formulas as before (at 8 a.m., 11 a.m., 2 p.m., and 5 p.m.), and blood was drawn for plasma glucose and immunoreactive insulin hourly from 8 a.m. to 2 p.m., and every half-hour from 2 to 5 p.m. A weighted average of both the glucose and insulin concentrations was obtained by assuming straight lines between points on a plot of concentration against the 9 hours of the test. The weighted average represents an estimate of the area units under a concentration "curve."

One additional patient, M.M., a 54-year-old woman (not listed in Table I) was studied for 3 weeks before

4 These assays were performed through the courtesy of Dr. Roger Unger, The University of Texas Southwestern Medical School, Dallas, Texas.

TABLE I

General description of patients studied

\begin{tabular}{|c|c|c|c|c|c|c|c|c|c|c|}
\hline \multirow[b]{3}{*}{ Patient } & \multirow[b]{3}{*}{ Age } & \multirow[b]{3}{*}{ Sex } & & & \multirow[b]{3}{*}{ Height } & \multirow{3}{*}{$\begin{array}{c}\text { Relative } \\
\text { weight } \dagger\end{array}$} & \multicolumn{4}{|c|}{ Clinical characteristics $\ddagger$} \\
\hline & & & \multicolumn{2}{|c|}{ Weight* } & & & \multirow[b]{2}{*}{ ASHD } & \multirow[b]{2}{*}{ ASO } & \multicolumn{2}{|c|}{ Xanthomata } \\
\hline & & & HF & $\mathrm{HC}$ & & & & & Tendon & Tuberous \\
\hline & years & & \multicolumn{2}{|c|}{$\mathrm{kg}$} & $\mathrm{cm}$ & & & & & \\
\hline 1. W.W. & 56 & $\mathbf{M}$ & 65.2 & 65.4 & 169 & 104.2 & $\mathrm{O}$ & $\mathrm{O}$ & $\mathrm{O}$ & $\mathrm{O}$ \\
\hline & 48 & $\mathbf{M}$ & 73.9 & 74.5 & 174 & 111.2 & $\mathrm{X}$ & $\mathrm{X}$ & $\mathrm{X}$ & $\mathrm{O}$ \\
\hline 3. F.W. & 45 & $\mathrm{~F}$ & 65.4 & 66.0 & 163 & 121.2 & $\mathrm{X}$ & $\mathrm{O}$ & $\mathrm{X}$ & $\mathrm{O}$ \\
\hline 4. G.B. & 52 & $\mathbf{M}$ & 72.9 & 74.5 & 171 & 108.0 & $\mathrm{X}$ & $\mathrm{O}$ & $\mathrm{O}$ & $\mathrm{O}$ \\
\hline 5. N.T. & 39 & $\mathbf{M}$ & 66.0 & 67.0 & 174 & 100.4 & $\mathrm{X}$ & $\mathrm{O}$ & $\mathrm{O}$ & $\mathrm{O}$ \\
\hline 6. L.Mc. & 52 & $\mathbf{M}$ & 77.2 & 78.4 & 171 & 110.7 & $\mathrm{X}$ & $\mathrm{O}$ & $\mathrm{O}$ & 0 \\
\hline 7. C.B. & 54 & $\mathbf{M}$ & 69.4 & 70.5 & 175 & 103.5 & $\mathrm{X}$ & $\mathrm{O}$ & $\mathrm{O}$ & $\mathrm{O}$ \\
\hline 8. E.M. & 48 & $\mathbf{M}$ & 78.4 & 80.6 & 179 & 111.5 & 0 & $\mathrm{O}$ & $\mathrm{O}$ & $\mathrm{O}$ \\
\hline 9. R.L. & 51 & $\mathbf{M}$ & 77.2 & 77.9 & 183 & 105.8 & $\mathrm{X}$ & $\mathrm{O}$ & $\mathrm{O}$ & $\mathrm{O}$ \\
\hline 10. J.H. & 50 & $\mathbf{M}$ & 89.4 & 91.2 & 180 & 116.6 & $\mathrm{X}$ & $\mathrm{O}$ & $\mathrm{O}$ & 0 \\
\hline 11. S.S. & 39 & $\mathbf{M}$ & 90.5 & 91.1 & 178 & 121.0 & $\mathrm{X}$ & $\mathrm{O}$ & $\mathrm{O}$ & $\mathrm{O}$ \\
\hline 12. R.N. & 47 & $\mathbf{M}$ & 71.3 & 71.8 & 173 & 108.7 & $\mathrm{X}$ & $\mathrm{O}$ & $\mathrm{O}$ & $\mathrm{O}$ \\
\hline 13. M.F. & 61 & $\mathrm{~F}$ & 57.7 & 59.4 & 160 & 111.1 & $\mathrm{X}$ & $\mathrm{O}$ & $\mathrm{O}$ & $\mathrm{O}$ \\
\hline 14. E.C. & 40 & $\mathrm{M}$ & 89.0 & 89.8 & 165 & 136.9 & $\mathrm{X}$ & $X$ & $\mathrm{O}$ & $\mathrm{X}$ \\
\hline 15. P.G. & 52 & $\mathbf{M}$ & 73.7 & 74.5 & 178 & 106.8 & $\mathrm{X}$ & $X$ & $\mathrm{O}$ & $\mathrm{O}$ \\
\hline
\end{tabular}

* Mean daily body weights during high fat (HF) and high carbohydrate (HC) diets.

$\dagger$ Relative weight $=$ per cent of ideal weight calculated from Metropolitan Life Insurance Co. tables.

$\ddagger \mathrm{X}=$ characteristic present; $\mathrm{O}=$ characteristic not present. ASHD = arteriosclerotic heart disease, either angina pectoris or previous myocardial infarction; ASO $=$ arteriosclerosis obliterans. 
TABLE II

Effect of diet on plasma lipid concentration

\begin{tabular}{|c|c|c|c|c|c|c|c|c|c|c|c|}
\hline \multirow[b]{3}{*}{ Patient } & \multirow{2}{*}{\multicolumn{3}{|c|}{$\frac{\text { High fat period }}{\text { Plasma lipids* }}$}} & \multicolumn{8}{|c|}{ High carbohydrate period } \\
\hline & & & & \multicolumn{5}{|c|}{ Triglycerides } & \multicolumn{3}{|c|}{$\begin{array}{c}\text { Means of } 1 \text { through } \\
4 \text { weeks }\end{array}$} \\
\hline & TG & Chol & $\overrightarrow{\mathrm{PL}}$ & 1 week & 2 weeks & 3 weeks & 4 weeks & Terminal† & TG & Chol & PL \\
\hline & \multicolumn{3}{|c|}{$m g / 100 \mathrm{ml}$ plasma } & \multicolumn{5}{|c|}{$m g / 100 m l$ plasma } & \multicolumn{3}{|c|}{$m g / 100 \mathrm{ml}$ plasma } \\
\hline 1. W.W. & 72 & 134 & 207 & 122 & 97 & 121 & 112 & $122\left(5 \frac{1}{2}\right)$ & 113 & 121 & 213 \\
\hline 2. J.P. & 158 & 352 & 303 & 169 & 200 & 179 & 172 & $205(6)$ & 180 & 361 & 231 \\
\hline 3. F.W. & 88 & 351 & 395 & 151 & 218 & 210 & 190 & (4) & 192 & 451 & 446 \\
\hline 4. G.B. & 122 & 196 & 205 & 286 & 288 & 306 & 323 & $286(6)$ & 301 & 217 & 241 \\
\hline 5. N.T. & 199 & 231 & 247 & 286 & 294 & 382 & & (3) & 321 & 270 & 264 \\
\hline 6. L.Mc. & 138 & 198 & 234 & 348 & 436 & 394 & 452 & $503\left(5 \frac{1}{2}\right)$ & 408 & 250 & 312 \\
\hline 7. C.B. & 110 & 174 & 200 & 449 & 436 & & & (2) & 443 & 207 & 263 \\
\hline 8. E.M. & 125 & 196 & 188 & 507 & 466 & 572 & 470 & $360\left(6 \frac{1}{2}\right)$ & 504 & 218 & 257 \\
\hline 9. R.L. & 110 & 254 & 250 & 620 & 563 & 706 & 510 & (4) & 600 & 308 & 390 \\
\hline 10. J.H. & 267 & 179 & 236 & 741 & 898 & 744 & 898 & (4) & 820 & 240 & 396 \\
\hline 11. S.S. & $1,101(738) \ddagger$ & 356 & 477 & 918 & 1,000 & 785 & & (3) & 901 & 290 & 406 \\
\hline 12. R.N. & 196 & 225 & 236 & 849 & 1,053 & 1,134 & & (3) & 1,012 & 279 & 338 \\
\hline 13. M.F. & 385 & 127 & 191 & 1,020 & 1.030 & & & (2) & 1,025 & 166 & 268 \\
\hline 14. E.C. & 650 & 251 & 296 & 971 & 1,025 & 1,052 & 1,060 & $974(7)$ & 1,027 & 309 & 387 \\
\hline 15. P.G. & $877(710)$ & 349 & 398 & & 1,714 & 1,489 & 1,346 & $1,408(5)$ & 1,516 & 444 & 606 \\
\hline Group means & 305 & 238 & 271 & & & & & & 624 & 276 & 335 \\
\hline
\end{tabular}

* $\mathrm{TG}=$ triglyceride ; chol $=$ cholesterol $; \mathrm{PL}=$ phospholipid.

t The number in parentheses after the terminal triglyceride value represents the total duration of the period in weeks. The terminal value is the final triglyceride value for periods exceeding 4 weeks.

$\ddagger$ The values in parentheses were obtained by subtraction of the chylomicron particulate triglyceride (derived from dietary fat, see Results) from total plasma triglyceride.

surgical removal of an insulin-secreting pancreatic adenoma. Her diet was derived from solid foods and contained approximately $350 \mathrm{~g}$ of carbohydrate per day. In addition to solid foods, consumed in frequent meals between 8 a.m. and 8 p.m., she received $150 \mathrm{~g}$ of glucose intravenously between 8 p.m. and 8 a.m. On 5 successive days food was withheld at 8 a.m., and blood was obtained at $8,9,10$, and 11 a.m. for measurement of glucose, immunoreactive insulin, and triglyceride concentrations.

\section{Results}

Effect of diet on plasma lipid concentrations. The plasma triglyceride, cholesterol, and phospholipid concentrations present in the 15 patients when on the high fat and high carbohydrate diets are seen in Table II. For the high fat period, the average values are listed, and each number is derived from the mean of 4 to 16 samples obtained twice weekly. Since it has been suggested that the triglyceride response to a high carbohydrate diet may be abolished with time (19), weekly triglyceride values (mean of biweekly measurements) are given for the high carbohydrate period. In seven patients, the high carbohydrate period lasted for more than 4 weeks, and the triglyceride values for the terminal week are also seen in Table II. The mean lipid values for the high carbohydrate period are the average of weekly concentrations during the first 4 weeks.
The patients are listed in order of increasing mean triglyceride concentration. It should be noted that in patients with the most elevated high carbohydrate triglycerides, there also was persistence of moderate hypertriglyceridemia (above $300 \mathrm{mg}$ per $100 \mathrm{ml}$ plasma) on the high fat diet (Table II). This phenomenon is noted in patients M.F., E.C., P.G., and S.S., but it is shown most clearly in patient S.S., who alone had a higher triglyceride concentration on the high fat than on the high carbohydrate diet. Therefore, all patients but S.S. had some degree of rise in triglyceride concentration when changed from the high fat diet to the high carbohydrate diet. However, activities of plasma postheparin lipolytic activity of patients S.S. and P.G. (the two with the highest "high fat" triglyceride levels) were within normal limits, ${ }^{5}$ indicating that they do not have fat-induced lipemia $(8,20)$. Also, when the contribution of dietary fat as plasma chylomicron triglyceride (21) was subtracted from the triglycerides of patient S.S., the high fat triglyceride value was appreciably less than the mean value of the high carbohydrate period (see second footnote to Table II). Plasma cholesterol and phospholipid changes

5 These analyses were performed through the kindness of Dr. Donald Fredrickson, National Institutes of Health, Bethesda, Md. 
generally paralleled the triglycerides but were lesser in magnitude.

Effect of chlorpropamide on plasma triglyceride concentration. Eight patients received $125 \mathrm{mg}$ of chlorpropamide per day for a 4-week period while on a high carbohydrate diet in an attempt to lower the triglyceride concentration. Four of these patients (L.Mc., J.F., E.C., and P.G.) had mildly abnormal oral glucose tolerance tests by the criteria of Fajans and Conn (22). However, in all cases fasting blood glucose concentration was less than $100 \mathrm{mg}$ per $100 \mathrm{ml}$ when tested before chlorpropamide, and in no instance was hypoglycemia detected with administration of this drug. The results of these experiments are seen in Table III. Each weekly value for triglyceride concentration is the average of two determinations, and, as before, the weekly and terminal triglyceride values are illustrated for each patient.

Ideally, all patients would have had three consecutive high carbohydrate dietary periods, with chlorpropamide administered during the middle period. This was achieved only in three patients. and the variation in experimental design makes statistical evaluation difficult. Analysis of two consecutive dietary periods, in which chlorpropamide was given during the second period, was possible in seven patients. By use of either the Wilcoxon signed ranks test $(\mathrm{p}=0.04)$ or the $t$ test $(p=0.03)$, chlorpropamide significantly lowered plasma triglyceride concentration. However, the magnitude of the chlorpropamide effect was not very great in most patients, and it is possible that this was a function of time rather than treatment. Consequently, we felt that additional investigation will be necessary to establish the effectiveness of chlorpropamide in lowering triglycerides.

Correlation of plasma lipid measurements and relative body weight with plasma glucose and insulin values. Correlation between the mean plasma triglyceride concentration attained on either diet was sought with the following: $a$ ) the mean of the fasting, 1-, 2-, and 3-hour blood glucose values of a standard oral glucose tolerance test done just before beginning the special diets; $b$ ) the mean

TABLE III

Effect of chlorpropamide on plasma triglyceride

\begin{tabular}{|c|c|c|c|c|c|c|c|}
\hline \multirow[b]{2}{*}{ Patient } & \multirow[b]{2}{*}{ Test period* } & \multicolumn{5}{|c|}{ Weeks of high carbohydrate diet } & \multirow{2}{*}{$\begin{array}{c}\text { Mean of } \\
\text { weeks 1-4 }\end{array}$} \\
\hline & & 1 & 2 & 3 & 4 & Terminalt & \\
\hline & \multicolumn{7}{|c|}{ mg triglycerides $/ 100 \mathrm{ml}$ plasma } \\
\hline J.P. & $\underset{\mathrm{HC}}{\mathrm{HC}}+$ chlor & $\begin{array}{l}192 \\
169\end{array}$ & $\begin{array}{l}214 \\
200\end{array}$ & $\begin{array}{l}196 \\
179\end{array}$ & $\begin{array}{l}180 \\
172\end{array}$ & $\begin{array}{l}179(8) \\
205(6)\end{array}$ & $\begin{array}{l}196 \\
180\end{array}$ \\
\hline F.W. & $\begin{array}{l}\mathrm{HC} \\
\mathrm{HC}\end{array}+$ chlor & $\begin{array}{l}151 \\
201 \\
282\end{array}$ & $\begin{array}{l}218 \\
193 \\
238\end{array}$ & $\begin{array}{l}210 \\
147 \\
203\end{array}$ & $\begin{array}{l}190 \\
161 \\
198\end{array}$ & $\begin{array}{r}(4) \\
(4) \\
222(5)\end{array}$ & $\begin{array}{l}192 \\
176 \\
230\end{array}$ \\
\hline L.Mc. & $\begin{array}{l}\mathrm{HC} \\
\mathrm{HC}+\text { chlor }\end{array}$ & $\begin{array}{l}348 \\
398\end{array}$ & $\begin{array}{l}436 \\
311\end{array}$ & $\begin{array}{l}394 \\
346\end{array}$ & $\begin{array}{l}452 \\
348\end{array}$ & $\begin{array}{l}503\left(5 \frac{1}{2}\right) \\
412(6)\end{array}$ & $\begin{array}{l}408 \\
351\end{array}$ \\
\hline M.F. & 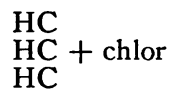 & $\begin{array}{l}437 \\
284 \\
237\end{array}$ & $\begin{array}{l}529 \\
371 \\
384\end{array}$ & $\begin{array}{l}517 \\
310 \\
376\end{array}$ & $\begin{array}{l}384 \\
246 \\
304\end{array}$ & $\begin{array}{r}322(6) \\
(4) \\
242(5)\end{array}$ & $\begin{array}{l}467 \\
303 \\
350\end{array}$ \\
\hline E.M. & $\stackrel{\mathrm{HC}}{\mathrm{HC}}+$ chlor & $\begin{array}{l}507 \\
343\end{array}$ & $\begin{array}{l}466 \\
332\end{array}$ & $\begin{array}{l}572 \\
312\end{array}$ & $\begin{array}{l}470 \\
212\end{array}$ & $\begin{array}{l}360\left(6 \frac{1}{2}\right) \\
217(7)\end{array}$ & $\begin{array}{l}504 \\
300\end{array}$ \\
\hline R.N. & $\begin{array}{l}\mathrm{HC} \\
\mathrm{HC}\end{array}+$ chlor & $\begin{array}{r}1,199 \\
775 \\
849\end{array}$ & $\begin{array}{r}547 \\
735 \\
1,053\end{array}$ & $\begin{array}{r}849 \\
714 \\
1,134\end{array}$ & $\begin{array}{l}877 \\
592\end{array}$ & $\begin{array}{c}(4) \\
734\left(5 \frac{1}{2}\right) \\
(3)\end{array}$ & $\begin{array}{r}868 \\
704 \\
1,012\end{array}$ \\
\hline E.C. & 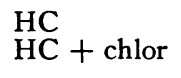 & $\begin{array}{r}1,202 \\
780\end{array}$ & $\begin{array}{r}1,036 \\
856\end{array}$ & $\begin{array}{r}755 \\
1,075\end{array}$ & $\begin{array}{r}1,121 \\
969\end{array}$ & $\begin{array}{l}(4) \\
(4)\end{array}$ & $\begin{array}{l}920 \\
971\end{array}$ \\
\hline P.G. & $\begin{array}{l}\mathrm{HC} \\
\mathrm{HC}+\text { chlor }\end{array}$ & & 1,714 & $\begin{array}{l}1,489 \\
1,223\end{array}$ & $\begin{array}{l}1,346 \\
1,713\end{array}$ & $\begin{array}{l}1,408(5) \\
1,220(8)\end{array}$ & $\begin{array}{l}1,516 \\
1,468\end{array}$ \\
\hline
\end{tabular}

*All test periods were consecutive. $\mathrm{HC}=$ high carbohydrate; chlor $=$ chlorpropamide.

$\dagger$ The terminal value is the final triglyceride value of periods exceeding 4 weeks. The number in parentheses represents the total duration of the test period in weeks. 
TABLE IV

Summary of data used in correlation of plasma lipid measurements with glucose and insulin values

\begin{tabular}{|c|c|c|c|c|c|c|c|c|c|c|c|c|c|}
\hline \multirow[b]{3}{*}{ Patient } & \multirow{2}{*}{\multicolumn{3}{|c|}{$\frac{\text { Ad libitum diet }}{\text { Glucose tolerance test* }}$}} & \multicolumn{5}{|c|}{ High fat diet } & \multicolumn{5}{|c|}{ High carbohydrate diet } \\
\hline & & & & \multicolumn{3}{|c|}{ Plasma lipids } & \multirow{2}{*}{$\begin{array}{c}\text { Glucose } \\
\text { areat }\end{array}$} & \multirow{2}{*}{$\begin{array}{l}\text { Insulin } \\
\text { areaf }\end{array}$} & \multicolumn{3}{|c|}{ Plasma lipids } & \multirow{2}{*}{$\underset{\text { area }}{\text { Glucose }}$} & \multirow{2}{*}{$\begin{array}{c}\text { Insulin } \\
\text { area }\end{array}$} \\
\hline & cose & lin & ILA & Chol & PL & TG & & & Chol & PL & TG & & \\
\hline & $100 \mathrm{mg} /$ & $\mu U / m l$ & $\mu U / m l$ & \multicolumn{3}{|c|}{$m g / 100 m l$} & \multicolumn{7}{|c|}{$\mathrm{mg} / 100 \mathrm{ml}$} \\
\hline 1. W.W. & 92 & 42 & 250 & 134 & 207 & 72 & 791 & 384 & 121 & 213 & 113 & 901 & 446 \\
\hline 2. J.P. & 80 & 77 & 209 & 352 & 303 & 158 & 998 & 274 & 361 & 231 & 180 & 938 & 268 \\
\hline 3. F.W. & 78 & 58 & 477 & 351 & 395 & 88 & & & 451 & 446 & 192 & & \\
\hline 4. G.B. & 100 & & 580 & 196 & 205 & 122 & 921 & 189 & 217 & 241 & 301 & 1,012 & 887 \\
\hline 5. N.T. & 93 & 82 & 242 & 231 & 247 & 199 & 879 & 156 & 270 & 264 & 321 & 985 & 166 \\
\hline 6. L.Mc. & 111 & & 890 & 198 & 234 & 138 & & & 250 & 312 & 408 & & \\
\hline 7. C.B. & 125 & 343 & 803 & 174 & 200 & 110 & & & 207 & 263 & 443 & & \\
\hline 8. E.M. & 111 & 76 & 239 & 196 & 188 & 125 & 911 & 230 & 218 & 257 & 504 & 1,089 & 647 \\
\hline 9. R.L. & 82 & 87 & 252 & 254 & 250 & 110 & & & 308 & 390 & 600 & & \\
\hline 10. J.H. & 98 & 101 & 580 & 179 & 236 & 267 & 1,039 & 283 & 240 & 396 & 820 & 1,158 & 1,019 \\
\hline 11. S.S. & 108 & & 1,345 & 356 & 477 & $1,101(738) \S$ & 1,023 & 337 & 290 & 406 & 901 & 1,240 & 1,828 \\
\hline 12. R.N. & 117 & 144 & 1,190 & 225 & 236 & 198 & 929 & 450 & 279 & 338 & 1,102 & 1,104 & 808 \\
\hline 13. M.F. & 158 & 172 & 830 & 127 & 191 & 385 & 1,118 & 669 & 166 & 268 & 1,025 & 1,715 & 1,963 \\
\hline 14. E.C. & 125 & 221 & 1,054 & 251 & 296 & 650 & & & 309 & 387 & 1,027 & & \\
\hline 15. P.G. & 131 & & 1,334 & 349 & 398 & $877(710) \S$ & 948 & 465 & 444 & 606 & 1,516 & 1,372 & 1,178 \\
\hline
\end{tabular}

* Mean of fasting, 1-, 2-, and 3-hour specimens. Insulin = immunoreactive insulin; ILA = insulin-like activity.

* Serum glucose area in $\mathrm{mg}$ per $100 \mathrm{ml}$ plasma during the period between 8 a.m. and 5 p.m. of "all-day" tests (see Methods).
† Plasma immunoreactive insulin area in microunits per milliliter during the all-day tests.

These values were reduced by subtracting chylomicron particulate triglyceride from total triglyceride. Only the first "uncorrected" value was used in seeking correlations.

of the fasting, 1-, 2-, and 3-hour values for insulin by bioassay and by immunoassay during the glucose tolerance test of the ad libitum diet period; c) the areas (in microunits per milliliter or milligrams per $100 \mathrm{ml}$ during 9 hours) of the hour and half-hour plasma insulin and glucose measurements during the all-day insulin-glucose tests performed at the end of each dietary period; and $d$ ) relative body weight (Table I). The data other than relative weight used for these correlations are seen in Table IV, and the results are listed in Tables V and VI.
Two methods of calculating correlation coefficients were used, the usual product moment correlation (PMC) (23) and the Spearman rank product moment correlation (RPMC) (24). Although these two methods gave closely similar results, correlations were generally higher with the rank method, a finding that suggests a nonlinear relationship between the variables tested. For simplicity, the comments that follow will emphasize the rank data. The most striking over-all impression is that all measurements of glucose and insulin response correlate very well (usu-

TABLE V

Correlation of tests done before dietary studies with lipid values and relative weight*

\begin{tabular}{|c|c|c|c|c|c|c|c|c|}
\hline \multirow[b]{3}{*}{ Test } & \multirow{3}{*}{$\begin{array}{l}\text { Statistical } \\
\text { method } \uparrow\end{array}$} & \multicolumn{6}{|c|}{ Lipid values } & \multirow{3}{*}{$\begin{array}{c}\text { Relative } \\
\text { weight }\end{array}$} \\
\hline & & \multicolumn{3}{|c|}{ High carbohydrate diet } & \multicolumn{3}{|c|}{ High fat diet } & \\
\hline & & TG & PL & Chol & TG & PL & Chol & \\
\hline \multirow{2}{*}{$\begin{array}{l}\text { Glucose } \\
\text { tolerance }\end{array}$} & PMC & 0.69 & 0.11 & -0.27 & 0.42 & 0.16 & -0.35 & 0.10 \\
\hline & RPMC & $\overline{0.76}$ & 0.13 & -0.26 & 0.53 & -0.30 & -0.35 & 0.01 \\
\hline \multirow{2}{*}{$\begin{array}{c}\text { Insulin-like } \\
\text { activity }\end{array}$} & PMC & 0.78 & 0.57 & 0.22 & 0.75 & 0.35 & 0.13 & 0.36 \\
\hline & RPMC & 0.73 & 0.60 & 0.15 & 0.59 & 0.23 & 0.09 & 0.18 \\
\hline \multirow{2}{*}{$\begin{array}{l}\text { Immuno- } \\
\text { reactive } \\
\text { insulin }\end{array}$} & PMC & 0.47 & -0.03 & -0.22 & 0.38 & -0.28 & -0.29 & 0.14 \\
\hline & RPMC & 0.74 & 0.20 & 0.08 & 0.56 & -0.21 & -0.24 & 0.09 \\
\hline
\end{tabular}

* Correlations are between the various "tests" on the vertical axis against items on the horizontal axis. Units for the measurements are as previously described. Underlined correlation coefficients are significantly different from zero, $\mathrm{p}<0.05$.

† PMC = product moment correlation, RPMC = rank product moment correlation. 
ally $>0.7$, Tables V and VI) with triglyceride response. Closer inspection of these data reveals that the correlations were generally higher for the high carbohydrate period than for the high fat period. It seems possible that this difference is due to inclusion of triglyceride values in the high fat data, which are spuriously high (Table II) due to their content of some exogenous (chylomicron) triglyceride. However, correlations were generally poorer $(<0.4)$ for these same glucose and insulin responses with either the plasma cholesterol and phospholipids or with relative weight. A somewhat greater correlation was present with phospholipid than with cholesterol, a finding consistent with the higher content of phospholipid than of cholesterol in the $\mathrm{S}_{\mathrm{f}}>20$ lipoprotein.

Metabolic studies on a patient with a pancreatic insulin-secreting adenoma. Table VII presents values from this patient (M.M.) for mean plasma levels of glucose, immunoreactive insulin, and triglycerides obtained immediately after her overnight glucose infusion, and hourly in the postinfusion period between 8 and 11 a.m. For comparison's sake, Table VII also includes similar data for two patients (group I) with the least, and four patients (group II) with the greatest, triglyceride responses to a high carbohydrate diet. The results show that the glucose values for both the immediate postinfusion sample and for the three subsequent fasting samples were very low in patient M.M. when compared with plasma glucose
TABLE VI

Correlation of all-day tests with dietary lipid responses and relative body weight*

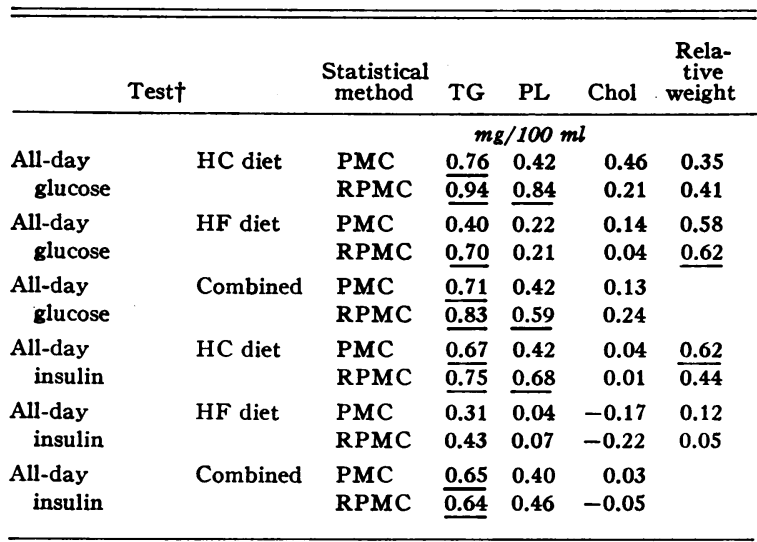

* Correlations are between the tests on vertical axis against items on the horizontal axis. See Table $V$ for explanation of abbreviations. Underlined correlation coefficients are significantly different from zero,

$\mathrm{p}<\mathrm{O}$.05. both diets.

concentrations of the other patients. On the other hand, insulin concentrations in plasma of patient M.M., drawn at the same time, are considerably higher than those found in patients with the lowest triglycerides either fasting or postprandially and are similar to the elevated plasma insulin values found in the patients with marked hypertriglyceridemia postprandially (group II). However, in spite of the increase in plasma insulin levels, plasma triglyceride concentration of patient M.M. was not elevated.

TABLE VII

Studies of a patient (M.M.) with a pancreatic islet cell tumor

\begin{tabular}{|c|c|c|c|c|c|}
\hline \multirow[b]{2}{*}{ Patients } & \multirow{2}{*}{$\begin{array}{c}\text { Fasting } \\
\text { plasma } \\
\text { triglyceride* }\end{array}$} & \multicolumn{2}{|c|}{ Plasma glucose } & \multicolumn{2}{|c|}{ Plasma insulin } \\
\hline & & Fasting & Postprandial & Fasting & Postprandial \\
\hline \multirow[b]{2}{*}{ M.M. } & \multirow{2}{*}{$\begin{array}{c}m g / 100 m l \\
196(3) \dagger\end{array}$} & \multicolumn{2}{|c|}{$m g / 100 m l$} & \multicolumn{2}{|c|}{$\mu U / m l$} \\
\hline & & $\begin{array}{l}47(12) \\
\pm 11\end{array}$ & $\begin{array}{l}58(8) \\
\pm 13\end{array}$ & $\begin{array}{l}126(11) \\
\pm 42\end{array}$ & $157(4)$ \\
\hline $\begin{array}{l}\text { Group I } \\
\text { (W.W. and } \\
\text { J.P.) }\end{array}$ & $148(2)$ & $80(2)$ & $101(6)$ & $25(2)$ & $82(2)$ \\
\hline \multirow{2}{*}{$\begin{array}{l}\text { Group II } \\
\text { (J.H., S.S., } \\
\text { M.F., P.G.) }\end{array}$} & \multirow[t]{2}{*}{$1,063(4)$} & \multirow[t]{2}{*}{$90(4)$} & $163(12)$ & \multirow[t]{2}{*}{$22(4)$} & $178(12)$ \\
\hline & & & \pm 50 & & \pm 127 \\
\hline
\end{tabular}

* Fasting refers to the samples obtained after an overnight fast (Groups I and II) or to the samples obtained from patient M.M. 1, 2, and 3 hours after cessation of the intravenous glucose infusions $(9,10$, and 11 a.m.). For Groups I and II, postprandial refers to the mean values of 1-, 2-, and 3-hour samples of the all-day test of the high carbohydrate period. For patient M.M., postprandial refers to the samples obtained at $8 \mathrm{a} . \mathrm{m}$. immediately before stopping the preceding 12-hour continuous intravenous glucose infusion.

$t$ The number in parentheses refers to the number of measurements used to obtain the mean. When present, numbers below the mean $= \pm$ standard deviation. 


\section{Discussion}

The effects of diets either low or high in carbohydrate on plasma triglyceride concentration have been documented in 15 patients. All demonstrated some increase in endogenous triglyceride concentration as a result of the high carbohydrate diet. Previous studies from our laboratory have established a precise relationship between the concentration and turnover rate of $S_{f}>20$ triglycerides in man (25) and demonstrated that increased hepatic triglyceride production is the primary cause of endogenous hypertriglyceridemia. The current studies were undertaken in an effort to correlate certain measures of glucose and insulin metabolism with the degree of increase in plasma triglyceride concentration (and hepatic production) resulting from a high carbohydrate diet. The wide variation in triglyceride response suggests that carbohydrate-induced lipemia (8) is not an all or none phenomenon, but rather that the majority of patients will increase their triglyceride production and concentration to a variable extent as a consequence of a high carbohydrate diet. Furthermore, our results indicate that one may accurately predict the magnitude of this triglyceride response. When tested during an ad libitum diet period, the more abnormal the glucose tolerance test and the higher the accompanying rises in plasma insulin-like activity and immunoreactive insulin, the greater the subsequent triglyceride rise on ingestion of a high carbohydrate diet. Finally, the degree of the triglyceride response on either a low or high carbohydrate diet correlated very well with the estimated integral of both plasma and glucose concentrations during the 9 hours of a representative day of ingestion of these diets.

If this apparent relationship is a causal one, there are at least two possible explanations. Hyperglycemia and hyperinsulinemia may cause hypertriglyceridemia, or conversely, a rise in plasma triglyceride concentration may secondarily increase plasma glucose and insulin concentrations. However, we find that the return of glucose and insulin values to normal antedates by a few days the return of elevated $S_{f}>20$ triglyceride to normal when hypertriglyceridemic patients are changed from high to low carbohydrate diets. Since we have previously found prolonged half- lives of $S_{f}>20$ triglyceride in such patients (26), we can predict this gradual return of triglyceride concentration to normal after the stimulus to lipid production is diminished. In view of these observations, the second alternative proposed above seems less likely but cannot be entirely excluded.

Although our data do not clearly distinguish between the possible relative importance of glucose and insulin in determining triglyceride response, certain comments are possible. First, it seems unlikely that plasma insulin concentration alone may control hepatic triglyceride synthesis and thereby plasma triglyceride concentration. Plasma triglycerides were not elevated in the subject with hyperinsulinism secondary to an islet cell adenoma, despite the ingestion of a high carbohydrate diet and the presence of plasma insulin levels comparable to those present in patients with marked lipemia. However, this patient also had hypoglycemia. In contrast, patients with lipemia had hyperinsulinism and moderate hyperglycemia. However, it does not follow that hyperglycemia alone is sufficient to produce hyperlipemia, for if this were the case, all patients with diabetes and hyperglycemia would have hyperlipemia. Since this is not so, hyperglycemia does not inevitably "cause" an elevation of plasma triglycerides. A clue to the solution of this problem may lie in the recent suggestion of Berson and Yalow (27) that patients with maturity onset diabetes may be separated into those with higher than normal and those with lower than normal plasma insulin concentrations. A few studies have been carried out in our laboratory on patients with maturity onset diabetes, hyperglycemia, and low levels of plasma insulin. None of these patients has developed hypertriglyceridemia in response to high carbohydrate diets. If these results are subsequently confirmed, they would suggest that hypertriglyceridemia can only develop in patients who have both hyperglycemia and hyperinsulinemia.

If, as much evidence indicates, the liver is readily permeable to glucose without the need for insulin facilitation of its transport (28), then the liver of certain patients will be subjected to episodes of marked hyperinsulinism and moderate hyperglycemia throughout much of the day. Could these factors directly stimulate an otherwise normal liver to synthesize larger quantities of triglyceride? Recent in vitro studies (29) sug- 
gest that this may well be, but experimental proof will require further knowledge of the rate-controlling steps in hepatic triglyceride synthesis and secretion in man. It would also be of interest to know the dependence of the hepatic triglyceride synthetic system on plasma free fatty acid concentrations in view of the evidence that FFA levels are modestly raised in hypertriglyceridemic subjects $(2,30)$. In any event, further study is needed to determine the relative importance of plasma glucose, plasma insulin, and plasma free fatty acids in control of triglyceride synthesis, secretion, and turnover.

If high insulin levels do enhance hepatic triglyceride synthesis and secretion in man, can this response be prevented in patients with hypertriglyceridemia? Evidence exists that chlorpropamide may produce a concomitant lowering of both blood glucose and insulin-like activity in patients with diabetes mellitus (12). If the modest triglyceridelowering effect of chlorpropamide reported here can be confirmed, this may be mediated by the action of this drug on glucose and insulin metabolism. Current studies include further evaluation of the effect of chlorpropamide and other oral hypoglycemic agents, weight reduction, altered rates of dietary carbohydrate ingestion, and high fat diets on the glucose, insulin, FFA, and triglyceride responses of individuals with either normal or elevated fasting blood sugars. Perhaps these observations will help to clarify further the relationship of various types of diabetes to premature atherosclerosis and hyperlipidemic states.

Finally, our data show clearly that within the broad spectrum of triglyceride response to a high carbohydrate diet, there is little evidence of "adaptability" of this response during periods of 4 to 6 weeks of high carbohydrate feeding. A report has appeared (19) of a return of triglycerides to previous levels after 6 months of continued ingestion of low fat diets in a group of white South African prisoners. Further study is needed to see if such adaptation would commonly occur in individuals whose propensity for lipemia is greater and if the adaptation is associated with a commensurate amelioration of the glucose and insulin abnormalities. Furthermore, it is important to know if the type of carbohydrate ingested determines the duration of these responses. Such studies would be relevant to the question of the wisdom of wide- spread use of high carbohydrate-low fat diets in the prevention of coronary arterial disease.

\section{Summary}

We administered alternating high fat and high carbohydrate diets to 15 patients and encountered a wide spectrum of plasma triglyceride response. An attempt was made to correlate this response with various measures of glucose and insulin metabolism. Glucose tolerance tests were performed just before the dietary studies, and the observed elevations of plasma glucose, insulin-like activity, and immunoreactive insulin correlated well with the magnitude of the triglyceride response that resulted from the subsequent ingestion of the higher carbohydrate diet. A similar high degree of correlation existed between the plasma triglyceride response and the average levels of plasma glucose and immunoreactive insulin reached during 9 hours of a representative day of ingestion of either the high fat or the high carbohydrate diet. However, despite the presence of hyperinsulinism, a high carbohydrate diet did not produce hypertriglyceridemia in a patient with hypoglycemia secondary to an islet cell adenoma. We suggest that hyperinsulinemia, in the presence of normal to moderately elevated levels of plasma glucose, may be an important cause of the enhanced hepatic triglyceride production that underlies endogenous hypertriglyceridemia.

\section{Acknowledgments}

We thank Mrs. Nancy Ballot and Mrs. Rosemarie Hess for technical assistance, Dr. Gerald Grodsky for assistance and advice in establishing the immunoassay procedure, Dr. Lester Salans for performing the assays for plasma insulin-like activity, and Dr. Gerald Chase for help in statistical analyses. We also thank the staff of the Stanford General Clinical Research Center for their excellent assistance in patient care and diet preparation.

\section{References}

1. Reaven, G., A. Calciano, R. Cody, C. Lucas, and R. Miller. Carbohydrate intolerance and hyperlipemia in patients with myocardial infarction without known diabetes mellitus. J. clin. Endocr. 1963, 23, 1013.

2. Kane, J. P., C. Longcope, F. C. Pavlatos, and G. M. Grodsky. Studies of carbohydrate metabolism in idiopathic hypertriglyceridemia. Metabolism $1965,14,471$. 
3. Knittle, J. L., and E. H. Ahrens, Jr. Carbohydrate metabolism in two forms of hyperglyceridemia. J. clin. Invest. 1964, 43, 485.

4. Davidson, P. C., and M. J. Albrink. Insulin resistance in hyperglyceridemia. Metabolism 1965, 14, 1059.

5. Reaven, G. M., J. W. Farquhar, L. B. Salans, R. C. Gross, and R. M. Wagner. Carbohydrate-induced lipemia (abstract). Clin. Res. 1964, 12, 277.

6. Reaven, G., A. Frank, R. Gross, L. Salans, and J. Farquhar. Glucose and insulin metabolism in carbohydrate-induced lipemia (abstract). Clin. Res. 1965, 13, 332.

7. Davidson, P., and M. Albrink. The relation of insulin responsiveness to plasma triglyceride levels (abstract). Clin. Res. 1965, 13, 71.

8. Ahrens, E. H., Jr., J. Hirsch, K. Oette, J. W. Farquhar, and $Y$. Stein. Carbohydrate-induced and fat-induced lipemia. Trans. Ass. Amer. Phycns 1961, 74, 134.

9. Kuo, P. T., and D. R. Bassett. Dietary sugar in the production of hyperglyceridemia. Ann. intern. Med. 1965, 62, 1199.

10. Ahrens, E. H., Jr., V. P. Dole, and D. H. Blankenhorn. The use of orally-fed liquid formulas in metabolic studies. Amer. J. clin. Nutr. 1954, 2, 336.

11. Nelson, N. A photometric adaptation of the Somogyi method for the determination of glucose. J. biol. Chem. 1944, 153, 375.

12. Salans, L. B., and G. M. Reaven. Effect of oral hypoglycemic agents on serum insulin-like activity of patients with various degrees of carbohydrate intolerance. Metabolism 1965, 14, 26.

13. Folch, J., M. Lees, and G. H. Sloane Stanley. A simple method for the isolation and purification of total lipides from animal tissues. J. biol. Chem. 1957, 226, 497.

14. Total cholesterol procedure N-24 in AutoAnalyzer Manual. Chauncey, N. Y., Technicon Instruments, 1964.

15. Bartlett, G. R. Phosphorus assay in column chromatography. J. biol. Chem. 1959, 234, 466.

16. Lofland, H. B., Jr. A semiautomated procedure for the determination of triglyceride in serum. Analyt. Biochem. 1964, 9, 393.
17. Plasma glucose procedure $\mathrm{N}-9$ in AutoAnalyzer Manual, Chauncey, N. Y., Technicon Instruments, 1964.

18. Grodsky, G. M., and P. H. Forsham. An immunochemical assay of total extractable insulin in man. J. clin. Invest. 1960, 39, 1070.

19. Antonis, A., and I. Bersohn. The influence of diet on serum-triglycerides. Lancet 1961, 1, 3.

20. Fredrickson, D. S., K. Ono, and L. L. Davis. Lipolytic activity of post-heparin plasma in hyperglyceridemia. J. Lipid Res. 1963, 4, 24.

21. Gordis, E. Demonstration of two kinds of fat particles in alimentary lipemia with polyvinylpyrrolidone gradient columns. Proc. Soc. exp. Biol. (N. Y.) 1962, 110, 657.

22. Fajans, S. S., and J. W. Conn. An approach to the prediction of diabetes mellitus by modification of the glucose tolerance test with cortisone. Diabetes 1954, 3, 296.

23. Cramer, H. Mathematical Methods of Statistics, 1st ed. Princeton, Princeton University Press, 1946, p. 265.

24. Kendall, M. G. Rank Correlation Methods. London, Charles Griffith, 1948.

25. Reaven, G. M., D. B. Hill, R. C. Gross, and J. W. Farquhar. Kinetics of triglyceride turnover of very low density lipoproteins of human plasma. J. clin. Invest. 1965, 44, 1826.

26. Farquhar, J. W., R. C. Gross, R. M. Wagner, and G. M. Reaven. Validation of an incompletely coupled two-compartment nonrecycling catenary model for turnover of liver and plasma triglyceride in man. J. Lipid Res. 1965, 6, 119.

27. Berson, S. A., and R. S. Yalow. Some current controversies in diabetes research. Diabetes 1965, 14, 549.

28. Cahill, G. F., Jr., J. Ashmore, A. E. Renold, and A. B. Hastings. Blood glucose and the liver. Amer. J. Med. 1959, 26, 264.

29. Salans, L. B., and G. M. Reaven. Effects of glucose and insulin on lipid metabolism in rat liver slices. Proc. Soc. exp. Biol. (N. Y.) In press.

30. Jakobson, T., A. Kahanpää, and E. A. Nikkilä. Serum lipids and glucose tolerance in subjects with a family history of diabetes mellitus. Acta med. scand. 1965, 178, 181. 